\title{
Barriers to the Take-up of Electronic Commerce among Small-Medium Sized Enterprises
}

\author{
Mark Stansfield \\ University of Paisley, Paisley, \\ Scotland, UK
}

mark.stansfield@paisley.ac.uk

\author{
Kevin Grant \\ Glasgow Caledonian University, \\ Scotland, UK
}

\author{
kevin.grant@gcal.ac.uk
}

\begin{abstract}
Since small-medium sized enterprises (SMEs) play a vital role within many major economies throughout the world, their ability to successfully adopt and utilize the Internet and electronic commerce is of prime importance in ensuring their stability and future survival. In this paper, initial findings will be reported of a study carried out by the authors into the use made of the Internet and electronic commerce and key issues influencing its use by SMEs. In order to broaden the scope of this paper, the results gained from the study will be compared with figures relating to businesses in the rest of Scotland and the UK, as well as the US, Canada and Japan, and European countries that include Sweden, Germany, France and Italy. The issues raised from this study will be compared with similar studies carried out in other countries such as Australia, New Zealand and British Columbia, as well as countries within the European Union in order to provide a wider meaningful international context for the results of the study.
\end{abstract}

Keywords: electronic commerce, small- medium sized enterprises, Internet related technologies

\section{Introduction}

Within the context of smaller companies, with electronic commerce, size and location can become irrelevant in which small companies can, in theory, have access to the same global market places as large companies. However, for smaller companies, electronic commerce provides particular challenges if they are to survive and flourish in the face of competition from larger companies who have more resources, technical expertise and capital. A broad perspective with regard to electronic commerce is taken in this paper, in that electronic commerce will be viewed within the context of performing any business process electronically. This may utilise a wide range of technologies that include electronic data interchange (EDI), e-mail, the Internet, the World Wide Web, Intranets and Extranets.

This research study set out to find out what the main issues and barriers were with regard to the level of Internet and electronic commerce adoption and activity, particularly among micro and small businesses. These types of businesses play a vital role within many economies globally. For example, there are 19 million SMEs in the European Union (EU) alone in which they make up over $99 \%$ of enterprises in most EU member states (EBPG, 2002). The study described in this paper focus on small businesses in Lan-

Material published as part of these proceedings, either on-line or in print, is copyrighted by Informing Science. Permission to make digital or paper copy of part or all of these works for personal or classroom use is granted without fee provided that the copies are not made or distributed for profit or commercial advantage AND that copies 1) bear this notice in full and 2) give the full citation on the first page. It is permissible to abstract these works so long as credit is given. To copy in all other cases or to republish or to post on a server or to redistribute to lists requires specific permission from the publisher at Publisher@InformingScience.org arkshire, an area located within West Central Scotland where micro and small businesses play a vital role within the economy. The results and issues arising from the study are placed within an international context with comparisons made to similar studies conduc ted elsewhere.

The vast majority of businesses in this study are classified as micro and small. Micro businesses 
(employing less than 9 employees) made up $69 \%$ of the respondents. A further $23 \%$ were small bus inesses employing between 10 and 49 employees. Business ownership tended to be highest in the middle age group, with $34 \%$ of owners being in the 35-44 age group and 31\% were in the $45-54$ age group. $15 \%$ of the respondents were female. Nearly $40 \%$ of the firms rely on local markets for $75 \%$ of their sales. Under $20 \%$ of the sample sell into the European market and for the majority, this constitutes less than $25 \%$ of their sales. Still fewer firms sell into non-EU overseas markets. The majority of respondents stated that their business objective was for either moderate or substantial growth. There was some evidence that younger business owners are more likely to favour substantial growth than older business owners.

\section{Factors Affecting IT and Internet Adoption within an SME Context}

In terms of the factors that influence the successful adoption Internet related technologies within SMEs, a number of authors (e.g. Chau, 2001; Mehrtens et al., 2001) identify three major factors, namely perceived benefits, organisational readiness and external pressure. In relation to perceived benefits, these include increased sales, improved communications with customers, vendors and employees, faster responses to customer inquiries and easier order tracking (Baldwin et al., 2000). However, SME managers need to be convinced of the benefits before fully adopting the technology, in which some managers do not feel that Internet technologies provide a significant improvement in service, compared with traditional methods (Marshall et al., 2000; Mehrtens et al., 2001; EBPG, 2002). Also highlighted in the literature, is the significant role regarding the attitude of the owner towards IT adoption (Levy and Powell, 2002; Chong, 2001). Often the more successful companies that embrace IT and Internet technologies are the ones where the owner takes on the role of the innovation champion of the IT adoption. In addition, such champions will have a reasonable level of knowledge and understanding regarding the specific techno logy.

Developing a clear and explicit strategy and careful planning is regarded as being an important step towards managers fully appreciating the potential of the Internet and maximising the benefits that it may provide (Lymer et al., 1999). For example, SME managers often find difficulties in appreciating the value of intangible benefits such as improved company image which can add to the feeling of uncertainty regarding the value and impact of the Internet (Marshall et al., 2000).

In terms of financial resources, whilst some studies highlight this as not having a major influence on the decision to adopt Internet technologies (Mehrtens et al., 2001), other studies highlight the situation that due to limited resources (e.g. financial, time, management personnel), SMEs cannot afford to experiment with these technologies and make expensive mistakes (EBPG, 2002). Consequently, this leads many SME managers to adopt a 'wait and see' attitude regarding the adoption of Internet technologies and electronic commerce models in order to minimise risks (EBPG, 2002).

Significant benefits may accrue to those small businesses that are willing to change their organisation and business processes to fully exploit the opportunities offered by electronic commerce (Baldwin et al., 2000). At the lowest levels of adoption, small businesses can use the Internet to surf and carry out basic market research. Having a virtual presence in the form of a web site is also within reach of most SMEs. However, studies have shown that there is little evidence of SMEs making the necessary internal changes needed in order to fully exploit these opportunities (Marshall et al., 2000).

\section{The Research Study}

For many years, small businesses have played an important role in the Scottish economy, particularly since the decline of traditional industries such as shipbuilding, coal, steel and textiles. Scottish Office figures in the Scottish Economic Bulletin No. 58 (1998) show that in 1997 there were 296,640 enter- 
prises in Scotland of which, $98.2 \%$, were small, between 0 to 49 employees. With regard to medium sized firms, those between 50-249 employees, in 1997 there were 3,311 enterprises in Scotland of this size that accounts for $1.1 \%$ of the total number of enterprises. Campbell and MacDonald (1999) highlight that small firms make a significant and consistent contribution to job creation whatever the trade cycle is. Lanarkshire extends over an area of 859 square miles situated between Glasgow and Edinburgh and supports a population of 633,000. 1.5 million people live within 30 miles of Lanarkshire and 3 million people live within 1 hour, which is approximately $60 \%$ of the total Scottish population. Within Lanarkshire, 193,00 people are employed with 28\% employed in manufacturing and 30\% employed in services. Lanarkshire has managed to diversify away from an economy traditionally based on coal and steel to a wide range of other sectors.

The study followed a number of stages involving the use of both qualitative and quantitative data collection techniques and approaches. For the purposes of this paper the main emphasis is on the quantitative aspects, regarding connectivity and integration levels. The main data collection techniques included interviews that were carried out with 15 businesses in the area, a questionnaire that was sent to a sample of 2,500 small businesses and telephone interviews that were used to test for non-response error bias and to simultaneously encourage response to the questionnaire.

The vast majority of businesses in this study are classified as micro and small. Micro businesses (employing less than 9 employees) made up $69 \%$ of the respondents. A further $23 \%$ were small businesses employing between 10 and 49 employees. Business ownership tended to be highest in the middle age group, with $34 \%$ of owners being in the $35-44$ age group and $31 \%$ were in the $45-54$ age group. $15 \%$ of the respondents were female.

More than $80 \%$ of the businesses have been in existence for more than 3 years. Limited companies made up $48 \%$ of the sample while $30 \%$ of the businesses are registered as sole traders. $86 \%$ of the businesses were VAT registered and around a third reported a turnover between $£ 100,000-£ 500,000$. Businesses with a turnover of less than $£ 50,000$ made up $17 \%$ of the sample. A third of the firms came into the service category (business or otherwise). Retail, repair and wholesale made up around 20\%, while manufacturing made up $16 \%$ of the sample.

Nearly $40 \%$ of the firms rely on local markets for $75 \%$ of their sales. Under $20 \%$ of the sample sell into the European market and for the majority, this constitutes less than $25 \%$ of their sales. Still fewer firms sell into non-EU overseas markets. The majority of respondents stated that their business objective was for either moderate or substantial growth. There was some evidence that younger business owners were more likely to favour substantial growth than older business owners.

\section{Initial Results from the Research Study}

\section{Virtual Presence}

The first stage on the path to full adoption and integration of Internet related technology is the establishment of an on-line presence in the growth adoption module. The respondents were asked if they had, or planned to have a web site. $37 \%$ of respondents or nearly $52 \%$ of businesses connected to the Internet stated that they had a web page. In comparison the 2000 Scottish Enterprise Benchmarking Study put the Scottish figure at $65 \%$ for all businesses with a marketing web site. The Benchmarking Report puts the number of micro businesses in Scotland with marketing web sites at $41 \%$. The comparable unadjusted figure in this study is around $45 \%$. To place the results within an international context, figures produced by Scottish Enterprise Network (2000) for all businesses with a marketing web site, show that Sweden is the leading nation with $76 \%$, followed by the US (68\%), the UK (66\%), Germany (66\%) and Canada (65\%). However, what is surprising is given all the marketing of Scottish Enterprise's Connect Scotland initiatives is that a third of the sampled SMEs did not yet have a web presence. 


\section{Utilisation and Integration}

Establishing levels of connectivity and presence is only the first part of understanding how small businesses are utilising Internet related technology. In order to gain a clearer picture about actual levels of integration and penetration of the technologies into the businesses, the respondents were asked a number of specific questions about what they were currently using the Internet for, and what they intended to do so in the future. Table 1 gives a detailed breakdown of both current and planned usage of various aspects of Internet related technology.

For the majority of the firms, increasing their utilisation of the technology is part of their overall business strategy. Over $84 \%$ of all the respondents either have or plan to have a web presence. Overall however, the data paints a picture of businesses that currently use the technology mainly as a research tool for finding out information about competitors, customers and alternative supply sources. Passive surfing for information is the predominant feature. Market research related activities remain among the more

\begin{tabular}{|l|l||l|l|l|}
\hline $\begin{array}{l}\text { What is your Current } \\
\text { and Planned Use of the } \\
\text { Internet? }\end{array}$ & Yes & No & Planned & Total \\
\hline $\begin{array}{l}\text { To find out about com- } \\
\text { petitors }\end{array}$ & $234(66.7 \%)$ & $105(29.9 \%)$ & $12(3.4 \%)$ & $351(100 \%)$ \\
\hline $\begin{array}{l}\text { To find out about } \\
\text { customers }\end{array}$ & $214(61 \%)$ & $127(36.2 \%)$ & $10(2.8 \%)$ & $351(100 \%)$ \\
\hline $\begin{array}{l}\text { To find out about sup- } \\
\text { pliers }\end{array}$ & $201(57.4 \%)$ & $129(36.9 \%)$ & $20(5.7 \%)$ & $350(100 \%)$ \\
\hline $\begin{array}{l}\text { To provide product in- } \\
\text { formation }\end{array}$ & $189(53.8 \%)$ & $66(18.8 \%)$ & $96(27.4 \%)$ & $351(100 \%)$ \\
\hline $\begin{array}{l}\text { To set up web page } \\
\text { To purchase } \\
\text { goods/services }\end{array}$ & $182(51.7 \%)$ & $55(15.6 \%)$ & $115(32.7 \%)$ & $352(100 \%)$ \\
\hline $\begin{array}{l}\text { To build customer con- } \\
\text { nections }\end{array}$ & $163(46.6 \%)$ & $148(42.3 \%)$ & $39(11.1 \%)$ & $350(100 \%)$ \\
\hline $\begin{array}{l}\text { To monitor hits on web } \\
\text { site }\end{array}$ & $117(33.6 \%)$ & $164(47.2 \%)$ & $67(19.2 \%)$ & $348(100 \%)$ \\
\hline To sell goods/services & $92(26.2 \%)$ & $168(47.9 \%)$ & $91(25.9 \%)$ & $351(100 \%)$ \\
\hline $\begin{array}{l}\text { To give staff formal } \\
\text { training on the Internet }\end{array}$ & $83(23.7 \%)$ & $217(62.0 \%)$ & $50(14.3 \%)$ & $349(100 \%)$ \\
\hline To bid for contracts & $36(10.3 \%)$ & $280(80.4 \%)$ & $32(9.3 \%)$ & $348(100 \%)$ \\
\hline $\begin{array}{l}\text { To make staff changes } \\
\text { as a result of using the } \\
\text { Internet }\end{array}$ & $30(8.6 \%)$ & $312(89.4 \%)$ & $7(2.0 \%)$ & $349(100 \%)$ \\
\hline $\begin{array}{l}\text { To have a separate on- } \\
\text { line subsidiary }\end{array}$ & $24(6.9 \%)$ & $309(89.4 \%)$ & $13(3.7 \%)$ & $346(100 \%)$ \\
\hline
\end{tabular}

\section{Table 1: Current and planned use of the Internet and electronic commerce}

popular uses of the Internet and at the most active level the majority are supplying product information and using the medium as a communication device (particularly e-mail) to build up business connections. Searching for on-line suppliers was mentioned by $57 \%$ of firms as one of their main uses for the technology.

In terms of utilisation for trading purposes almost $51 \%$ (178) of businesses said they bought goods or services on-line; only $26 \%$ (92) reported that they sold goods and services in the same way. Only a small number of firms, nearly $9 \%$ (30) bid for contracts on the Internet. In total, nearly $7 \%$ (24) reported hav- 
ing a separate on-line subsidiary. Some evidence of the lack of impact that the technology has had on internal organisational processes comes from the small number of businesses, $8 \%$ who report having made any staff changes as a result of using the Internet.

When set against the wider international context, 29\% of all Scottish businesses can be classified as trading online, compared with Japan (8\%), France (9\%), Italy (11\%), Sweden (20\%), Canada (24\%), the US (26\%) and the UK (27\%) (Scottish Enterprise Network, 2000). Just over 44\% of all Scottish businesses order supplies online, whereas only $27 \%$ pay online. In Japan $15 \%$ order supplies online and $6 \%$ pay online, in the US 53\% order supplies online and 19\% pay online, in Sweden 50\% order supplies online and $23 \%$ pay online and in the UK $44 \%$ order supplies online and $28 \%$ pay online (Scottish Enterprise Network, 2000).

The rapid uptake of the technology by small businesses has not been matched by a similar rush to provide training support. For many of the respondents, most of the training that takes place is informal 'on the job'. This is a finding that reinforced the results from the initial interviews. Most of the respondents were unwilling to commit staff time to a technology in which the returns were uncertain. Formal training on using the Internet is given by less than $24 \%$ of the companies actually using the technology. This figure is lower than for micro businesses in Scotland as a whole (33\%). Set within an international context, the figure for Scotland in terms of offering formal IT training is quite low (58\%) when compared to Sweden (75\%), France (73\%) and Germany (71\%), but higher compared with Japan (41\%), Italy (47\%) and the US (50\%) (Scottish Enterprise Network, 2000).

\section{Perceptions and Attitudes}

In common with businesses in the rest of the UK, the firms in the Lanarkshire area are embracing Internet related technology. Only $4 \%$ of respondents for this survey stated that they thought their business would probably never go on-line. Overall perceptions of, and attitudes towards the technology are strongly positive. When respondents were asked about the relevance of the Internet for their businesses and whether it was a valuable business tool there was agreement, even among those firms not currently using the technology, that it was both relevant and valuable. (Tables 2 and 3)

Within an international context, in terms of the importance of electronic commerce to competitiveness in

\begin{tabular}{|l||l||l|l|l||}
\hline $\begin{array}{l}\text { Do you consider the Internet to be } \\
\text { a valuable business tool? }\end{array}$ & $\begin{array}{l}\text { Using } \\
\text { Internet }\end{array}$ & $\begin{array}{l}\text { Not using } \\
\text { Internet }\end{array}$ & Total & Percentage \\
\hline \hline Strongly disagree & 5 & 2 & 7 & 1.5 \\
\hline Disagree & 17 & 15 & 32 & 6.7 \\
\hline Neutral & 49 & 48 & 97 & 20.2 \\
\hline Agree & 129 & 65 & 194 & 40.5 \\
\hline Strongly agree & 135 & 14 & 149 & 31.1 \\
\hline Total & 335 & 144 & 479 & 100 \\
\hline
\end{tabular}

Table 2: Attitudes to the Internet as a valuable business tool

\begin{tabular}{|l||l||l||l||l||}
\hline \hline $\begin{array}{l}\text { Do you consider that the Internet } \\
\text { has no relevance? }\end{array}$ & $\begin{array}{l}\text { Using Inter- } \\
\text { net }\end{array}$ & $\begin{array}{l}\text { Not using } \\
\text { Internet }\end{array}$ & Total & Percentage \\
\hline \hline Strongly disagree & 176 & 20 & 196 & 40.6 \\
\hline Disagree & 99 & 56 & 155 & 32.1 \\
\hline Neutral & 46 & 47 & 93 & 19.2 \\
\hline Agree & 12 & 16 & 28 & 5.8 \\
\hline Strongly agree & 4 & 7 & 11 & 2.3 \\
\hline Total & 337 & 146 & 483 & 100 \\
\hline
\end{tabular}

Table 3: Attitudes to the Internet having no relevance 


\begin{tabular}{|l||l||l|l||}
\hline $\begin{array}{l}\text { What kind of impact do you con- } \\
\text { sider the Internet to have had? }\end{array}$ & $\begin{array}{l}\text { Number of re- } \\
\text { spondents }\end{array}$ & Percentage & $\begin{array}{l}\text { Percentage } \\
\text { of those using the Internet }\end{array}$ \\
\hline \hline A positive impact & 192 & $39.7 \%$ & 57.3 \\
\hline No impact & 109 & $22.5 \%$ & 32.5 \\
\hline A negative impact & 2 & $0.4 \%$ & 0.6 \\
\hline Don't know & 32 & $6.6 \%$ & 9.6 \\
\hline Don't use the Internet & 17 & $3.5 \%$ & \\
\hline Total & 352 & $72.7 \%$ & \\
\hline Invalid/missing details & 132 & $27.3 \%$ & \\
\hline Total & 484 & $100 \%$ & 100 \\
\hline
\end{tabular}

Table 4: The impact of the Internet on the responding bus inesses

the short to medium term, $72 \%$ of all Scottish companies considered it to be very important which compares favourably with France (52\%), Japan (53\%), the US (60\%), Canada (63\%) and Germany (71\%) (Scottish Enterprise Network, 2000).

Respondents using Internet related technologies were asked to give their overall assessment of the impact of the technology on their businesses (Table 4). Only a very small percentage, less than $1 \%$ report a negative impact for either the Internet or e-mail, but a much larger number report 'no impact' or are unsure of just what the impact has been. These figures may stem from the relatively short time that many firms have been on-line but allowing for this, investment in the technology is clearly an uncertain gamble for many. The evidence from the initial interviews suggested that Internet adoption is often for reactive reasons e.g. fear of being left behind, rather than proactive reasons i.e. to use the technology to do business differently.

Within the context of the UK as a whole, the main competition drivers among electronic commerce users include customer demand (68\%), improving the range and quality of services offered (70\%) and avoiding losing markets share to competitors already us ing electronic commerce (71\%) (Scottish Enterprise Network, 2000). 53\% of all Scottish businesses believe that electronic commerce is very important or essential to developing foreign markets. This compares with other countries such as Japan (44\%), the US (49\%), Sweden (41\%), Germany (51\%) and France (53\%). Countries where this figure was higher included Canada (54\%) and the UK (55\%) (Scottish Enterprise Network, 2000).

\section{Barriers to Internet and Electronic Commerce Take-up}

The questionnaire was designed to allow those businesses currently not connected the opportunity to rate a number of factors in terms of their importance in influencing the decision not to take-up the Internet and electronic commerce. Table 5 outlines the percentage of respondents who rated these factors as being important or very important.

Overall, the strongest factor to emerge in terms of barriers to take-up appears to be a lack of knowledge about the Internet and electronic commerce (52\%). Other factors that could be linked to this lack of knowledge include a lack of advice and support (45\%) and a lack of staff with IT skills (46\%). Related to the lack of IT skills was the fear that if they invested in their staff gaining these skills they would demand more money or leave to go and work elsewhere for more pay or better prospects.

Further research would be needed to investigate the exact nature of this knowledge gap and how much of a barrier it really is. Expense and complexity were viewed as being 'important' or 'very important' barrie rs by around $40 \%$ of respondents. A fear of being 'ripped off' and concerns over security were mentioned by around $30 \%$ in terms of their importance.

Within an international context, figures from Scottish Enterprise Network (2000) show that IT skills shortage was considered to be a barrier by $40 \%$ of non electronic commerce users in the UK, $15 \%$ in the 742 


\begin{tabular}{||l||l||}
\hline $\begin{array}{l}\text { Factors Influencing Decisions NOT to take-up the } \\
\text { Internet and electronic commerce }\end{array}$ & $\begin{array}{l}\text { \% Response who considered } \\
\text { Factors Important or Very } \\
\text { Important }\end{array}$ \\
\hline \hline A lack of knowledge & 52 \\
\hline Lack of time & 47 \\
\hline Lack of staff with IT skills & 46 \\
\hline A lack of advice and support & 45 \\
\hline Too expensive & 39 \\
\hline Too complex & 38 \\
\hline Few customers are on-line & 33 \\
\hline Not relevant to business & 33 \\
\hline A fear of being 'ripped off' & 31 \\
\hline Business too insecure & 28 \\
\hline Few suppliers are on-line & 27 \\
\hline Business too slow and disorganised & 26 \\
\hline Few competitors are on-line & 23 \\
\hline No wish to expand & 18 \\
\hline
\end{tabular}

\section{Table 5: Barriers to Internet and electronic commerce take-up for companies not currently connected to the Internet (Multiple answers were allowed in answer to this que stion)}

US and 30\% in Scotland as a whole. Lack of management commitment accounted for $39 \%$ in the UK, $47 \%$ in the US and $50 \%$ in Scotland as a whole. No tangible benefits accounted for $60 \%$ in the UK, $50 \%$ in the US and $63 \%$ in the whole of Scotland. High technology costs accounted for $54 \%$ in the UK, $74 \%$ in the US and $60 \%$ in the whole of Scotland.

\section{Issues Influencing the Use of Internet and Electronic Commerce among SMEs}

Overall the main use for the Internet related technology is for undertaking research activities, in particular, looking for new suppliers and customers and finding out about the activities of competitors. Whether this is part of a natural trend towards electronic commerce is debatable. Firms who had been on-line for more than two years were only marginally more likely to buy or sell via the Internet than firms who had gone on-line more recently. These findings appear to be in keeping with other studies carried out els ewhere in the world. For example, MacKay et al., (2001) who carried out a study of the impact of ele ctronic commerce on SMEs in British Columbia, found that most SMEs (82.4\%) reported using websites for information sharing with external shareholders.

There is truth in the on-line cliché that 'your competitors are only a couple of clicks away'. More distant on- line competitors may displace local suppliers. Clearly this is a simplification, but it could help explain this emerging e-trade gap. Evidence from the interview stage of the research reinforces these findings. It was noted that these on-line suppliers were often based at a considerable distance. For example, one company commented that they had ended a 20 -year relationship with a local supplier in favour of sourcing materials on- line from a company based in Scandinavia. Thus, small businesses that are failing to sell their goods and services on-line may be failing to make the strategic changes required to become e-businesses.

Given the implications of Internet based technology upon businesses, one might expect to observe significant organisational impact on internal structures and staff. However, only a small percentage of businesses reported making staff changes as a result of using Internet related technology. Similarly only a small number of respondents said that the technology had had any impact on their internal operations. This appears to be symptomatic of organisations that are 'bolting' the technology onto their existing 
structures and practices. The use of Internet related technology is mostly 'front end', i.e. typically static sites providing product information and contact details. This approach may be seen as the only option for many small firms who are uncertain about risking scare resources to a technology where the returns might be uncertain. Certainly the current high profile coverage of dot.com failures is scarcely likely to encourage small firms to take the electronic commerce road, particularly if it means major change and investment.

In the study, important factors that influenced companies not to adopt the Internet and electronic commerce included a lack of knowledge, a lack of skills and a lack of advice and support. The role of external support in convincing SMEs of the benefits of electronic commerce, as well as providing the knowledge and skills to be able to successfully adopt and further develop their electronic capabilities is of great importance. For example, even in Finland, which has one of the highest rates of Internet access (90\%), it is still perceived as being important to raise awareness among micro businesses (EBPG, 2002). Few companies adopt deliberate and explicit strategies with regard to electronic commerce (Marshall et al., 2000), mostly due to a lack of skills, knowledge and time. Education and training is viewed as being crucial to addressing the lack of readiness of SMEs in adopting and developing their electronic business capabilities (Chau, 2001). The reliance of SMEs on external resources and support is highlighted by MacKay et al., (2001) who found that in British Columbia, 78\% of SMEs rely to some extent on external resources to assist them in developing, managing and maintaining their websites. The Development of a comprehensive and co-ordinated netwo rk of support agencies will be crucial in providing education and training to SMEs. A step towards achieving this goal has already been taken in Europe with the setting up of the eEurope Go Digital initiative which is aimed at helping SMEs seize the opportunities provided by electronic commerce by benchmarking national and regional e-business policies for SMEs (EBPG, 2002).

\section{Conclusion}

The sharp rise in interest and usage of Internet related technology by small businesses in the Lanarkshire area clearly cannot be taken to imply that there will be any immediate or seamless transition to full blown electronic commerce. Most of the small firms are in the early stages of Internet adoption and few show any inclination to make the leap towards full integration or even attempting to explore how and where electronic commerce can be used to add and increase bus iness value.

The next stage of the study outlined in this paper is to investigate some of the issues that have emerged in more detail. One important issue appears to be 'e-awareness' and the provision of training and skills to micro and small businesses. Perry and Schnedier (2001) showed that mass media knowledge of the benefits of electronic commerce was not in itself sufficient to lead to adoption within the context of small businesses. Only $25 \%$ of the businesses provided formal training in the technology, which is not surprising given their size and limited resources. This has also been highlighted in other surveys by Local Enterprise Companies (e.g. Scottish Enterprise Renfrewshire), which identified a low level of training being carried out across all company size grouping, especially lowest among the smaller businesses. What is evident is that although local and national policy makers have achieved a certain degree of success in persuading SMEs to get online, there is still much work needed. Policy makers need to address the level of consultant support and ensure that SMEs feel that they are getting value for money. Policy makers also need to address the current attitudes and support mechanisms with regards to how to develop a positive approach to training staff with the skills needed to capitalise on Internet related technologies. 


\section{Acknowledgements}

The authors would like to thank Tom Scally from Bell College of Technology for his work in preparing the statistics, as well as all of the businesses that participated in the study for their valuable time and effort.

\section{References}

Baldwin, A., Lymer, A. \& Johnson, R. (2000). Business impacts of the Internet for small and mediumsized enterprises. In $E$ Commerce and V-Business: Business Models for Global Success (Eds: B. Hunt and S. Barnes) Oxford: ButterworthHeinemann. 103-120.

Scottish Enterprise Renfrewshire (2000). Benchmarking the Renfrewshire area-ICT: A survey of e-business readiness April/May 2000.

Chau, P. (2001). Inhibitors to EDI adoption in small businesses: An empirical investigation. Journal of Electronic Commerce Research, 2, 2, May 2001.

Chong, S. (2001). Electronic commerce adoption by small-medium sized enterprises in Australia and Singapore. Working Paper, School of Information Systems, Curtin University of Technology, Perth, Western Australia.

EBPG (2002). eEurope go digital: Benchmarking national and regional e-business policies for SMEs. Final report of the EBusiness Policy Group, 28 June 2002.

Lymer, A. (1999). UK business and the information superhighway: The impact of the Internet on SMEs. ACCA Occasional Research Paper 23.

MacKay, N., Gemino, A., Igbaria, M. \& Reich, B. (2001). The Impact of electronic commerce: A survey of small and medium-sized enterprises in British Columbia. Research Results, Simon Fraser University, British Columbia.

Marshall, P., Sor, R. \& McKay, J. (2000). An industry case study of the impacts of electronic commerce on car dealerships in Western Australia. Journal of Electronic Commerce Research, 1, 1, February 2000.

Mehrtens, J., Cragg, P.B. \& Mills, A.M. (2001). A model of Internet adoption by SMEs. Information and Management, 39. 165-176.

Scottish Enterprise Network. (2000). E-Business benchmarking 2000: An international benchmarking Study.

Scottish Enterprise Network. (2000). http://www.scottish-enterprise.com/businessdev/e-comm/ [last accessed $23^{\text {rd }}$ October 2002).

\section{Biographies}

Mark Stansfield is a lecturer in the School of Information and Communication Technologies at the University of Paisley and is Programme Leader of the MSc Management of eBusiness. He has a PhD in Information Systems and has published papers on information systems and e-business in a number of international journals. Main research and teaching interests include e-business, e-commerce, m-business, e-learning and information systems development. Mark is also the Reviews Editor of the International Journal of Information Management.

Kevin Grant is a Senior Lecturer in the Division of Business Information Management at Glasgow Caledonian University and Programme Leader of the MSc Information and Administrative Management $\mathrm{He}$ is currently conducting research towards a Doctorate of Education and has published papers in a number of international journals. Teaching and research interests include strategic information management and information systems. Kevin is also an Editorial Board Member of the Electronic Journal for Business Research Methods. 